\title{
The Shudder of a Cinephiliac Idea? Videographic Film Studies Practice as Material Thinking Catherine Grant ${ }^{1}$
}

I.

"In the face of the seemingly limitless possibilities, practice cannot know or preconceive its outcome. Rather, the new emerges through process as a shudder of an idea [...]." (Bolt 2004a)

"In a sense, the cinephiliac moment may be understood as a kind of mise-en-abyme wherein each spectator's obsessive relationship with cinema is embodied in its most concentrated form. [...] But if we see cinephiliac moments as the flashes of another history, how to develop that history?" (Keathley 2000)

"[I]t is in the joining of hand, eye and mind that material thinking occurs, but it is necessarily in relation to the materials and processes of practice, rather than through the 'talk,' that we can understand the nature of material thinking. Words may allow us to articulate and communicate the realisations that happen through material thinking, but as a mode of thought, material thinking involves a particular responsiveness to or conjunction with the intelligence of materials and processes in practice." (Bolt 2007, 30)

Long after the advent of the digital era, while the overwhelming majority of university-based film studies academics still choose to publish their critical, theoretical and historical research in conventional written formats, a small but growing number of scholars working on the moving image have begun to explore the online publication possibilities of the digital video essay. This multimedia form has come to prominence in recent years in much Internet-based cinephile and film critical culture (Keathley 2011). Interestingly, at least in relation to its transfer to an academic context, some of the video essay's emergent modes are especially indebted to the "provisional and subjective" traditions of the essay film (Scherer 2001, 14), much studied in written film scholarship. Indeed, the video essay format can inspire compelling work not only because, with its possibilities for direct audiovisual quotation, it can enhance the kinds of explanatory research that have always been carried out on films, but also precisely because of its potential for more "poetic", creative and performative critical approaches to moving image research (Grant 2013a). This new form also raises issues of medium-specificity in a context of long-established academic assessment standards and practices: for example, should we be aiming to "translate" the (often

\footnotetext{
${ }^{1}$ University of Sussex (UK).
} 
unspoken) norms and traditions of written film studies into audiovisual versions, or should we embrace from the outset the idea that we are creating ontologically new scholarly forms (Grant 2013c)?

While these questions are important and pressing, what I elect to focus on in this written reflection is less the finished forms of the emerging range of videographic film studies, less on their status as research outcomes, "outputs," or scholarly communications, as it were, and more on my experience of the "original and originary" (Bolt 2007, 27) audiovisual research processes involved in their production. One of the most important informants of my discussion here is the artist, fine art theorist, and proponent of practice-based approaches to research in the arts Barbara Bolt. Bolt has persuasively argued that philosopher Martin Heidegger's elaboration of handlability provides "a key to rethinking the conditions of possibility of creative practice" (Bolt 2004b, 6) as a form of understanding with the hands and eyes, which "operates in a different register from the representational paradigm of man-as-subject in relation to objects" (ibid.): "For Heidegger, handling is a relation of care and concernful dealings, not a relation where the world is set before us (knowing subjects) as an object." (Bolt 2004b, 6)

In what follows, I will consider, above all from a personal perspective looking back at just two of the sixty or so videos that I have made, some of the possibilities that their processes of handling offer for the production of new knowledge in research into cinephile practices and experiences, research that is forged out of the conjunction of the film object(s) to be studied, digital technologies of reproduction and editing tools, and the facticity of the researcher(s). I will argue that digital video is usefully seen not only as a promising communicative tool with different affordances than those of written text, but also as an important emergent cultural and phenomenological field for the creative practice of our work as film scholars. 
II.

"[T]here is always a personal edge to the mix of intellectual curiosity and fetishistic fascination." (Mulvey 2006, 145)

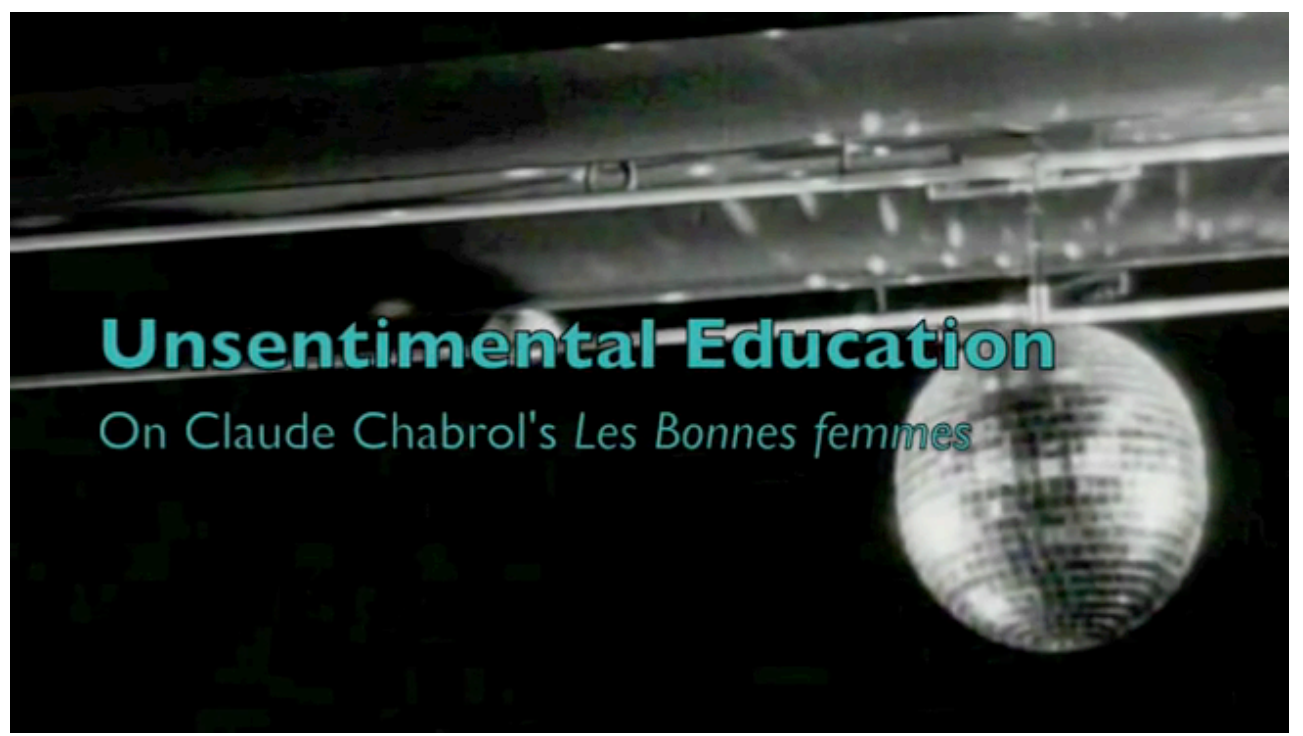

Figure 1: Screenshot from Unsentimental Education (Catherine Grant, 2009) | (c) Paris Film/Panitalia

Unsentimental Education (2009; see figure 1) was my first, rather tentative attempt at making a film-critical video essay for free online distribution. As I look back at it now I can see that this turn in my work was partly inspired by some of my earlier research on the emerging connoisseur culture of DVD “extras" (Grant 2008a). This had focused on the relationship between voiceover commentary and audiovisual extracts from the film deployed in many of those formats, and had examined how this digitally-enabled contiguity might help to turn "the 'original' (theatrical) experience of watching the film as fiction into one of watching it 're-directed' or literally reperformed, as a documentary, one in which the film's existing visual track is employed as graphic illustration of a teleological story of its own production" (Grant 2008a, 111). I was of course familiar with Laura Mulvey's ground-breaking written work, around ten years ago, on the new (and existing) material qualities of film in the age of video and digital technologies, and about "the space and time" new digital affordances seem to offer "for associative thought, [for] reflection on resonance and connotation, [for] the identification of visual clues, the interpretation of cinematic form and style, and, ultimately, personal reverie" (Mulvey 2006, 146-47). I had also seen one of the digital video experiments Mulvey had directed (2006, 172). Like other scholars, I had begun to connect some of the developments she examines with the burgeoning examples of videographic film studies appearing online from 2005 onwards, 
which were clearly part of a much wider field of production in online cinephile remix and film critical culture (Keathley 2011) and I had begun to explore these latter forms, in theory at least, at my research blog (Grant 2008b). I would never have predicted that I would go on to create such artefacts myself, however. I had always been a fairly conventional Film Studies academic: I saw writing about films and film culture as my "work," and I was generally keen to maintain the usual separation between "theory" and "practice." But, as Maria H. Loh notes, in an inspiring published conversation with Mulvey, "curiosity is the drive that can build a new kind of interactive spectatorship" (Loh 2007, my emphasis). As I was deeply curious about these new forms, and about what one might be able to explore with them, I very readily became an especially active kind of interactive and also, of course, at once "possessive" and "pensive" spectator (Mulvey 2006, 144).

What surprised me, after I had embarked on the necessary processes of sourcing, converting, importing, exploring, playing with and re-editing digitised film footage, was not only how straightforward it was to do all this, given the relatively user-friendly digital format-conversion and editing software that nowadays is available for free with many computers or online (see Mittell 2010); but also how much more I went on to learn about the form of the Claude Chabrol film that I had chosen to examine in these ways, as well as about my personal response to it. Les Bonnes femmes (The Good Time Girls, 1960) is a movie I have taught many times. I thought that I knew it very well, which was one of the reasons I had chosen to work on it. What I realised afterwards was that I had also been motivated by a desire to engage even more closely with this film's strangeness - its beguiling yet disturbing affect - a quality to which I have always been (perhaps obsessively) drawn, and one that neither I nor my students had been able to account for effectively in words, to my satisfaction at least, in numerous individual sequence analyses in university seminars.

Working closely on the digitised version of the film in my chosen iMovie video editing programme in some ways felt very much like studying it frame by frame on a flatbed editing table, as in the Film Studies classes of a mostly bygone era. It certainly introduced me to what Annette Michelson once described as the "heady delights $[\ldots]$ the euphoria one feels at the editing table $[\ldots]$ a sharpening cognitive focus and [...] a ludic sovereignty, grounded in that deep gratification of a fantasy of infantile omnipotence" (Michelson 1990, 22-23. Cited by Mulvey 2006, 193). Using this non-linear editing software also created the sensation of "touching the film object" (Grant 2012a), at least virtually, as a digital, or digitized, artefact accessed through a graphical user interface. Of course, this sensation did indeed turn on an active handling of it, one that involved eye/earhand-touch pad-virtual object/screen coordination and interaction, 
similar to the DVD-handling conjunction of eye-hand-remote control-virtual object/screen. But non-linear editing obviously offers the additional and constitutive affordances of extraction and reformation of the component parts of the film object. The extra ability to manipulate audiovisual material from the film in order to serve durational, motional, spatial and locational experiments - including: randomly generating a whole suite of frozen moments from its entire duration in the form of thumbnail images, and then regenerating these at different frame rates; freezing and zooming in or out of full frames; playing with different forms of altered motion and superimpositions; detaching the soundtrack and moving it around; creating new image-sound, image-image, and sound-sound juxtapositions helped me to arrive at a much more detailed, paradigmatic understanding of Les Bonnes femmes, of its constant moves from high to low, and its graphic matching, through these moves, of key shapes, like that of the statue at the beginning of the film. It also made much more palpable the film's brilliant thematic exploration of subjective experiences of spatiotemporality, as I shall go on to describe.

When I produced this first essay, though, I didn't have enough confidence in the process of making it to allow a completely intuitive, creative understanding of the film to emerge in the finished video. Unsentimental Education tries very hard (possibly too hard) to hit a lot of the bases I'd covered in my years of teaching the film re-presenting knowledge about it that I already knew. It also feels quite long to me now, at thirteen and a half minutes. Even its fairly sparse voiceover commentary (which, rather than pre-scripted, was at least largely improvised to accompany the re-editing - in other words, it was created as a kind of "antiphonal" response to what I was handling) seems too wordy to me now. But, regardless of its shortcomings as a finished essay, it was the practical experience of having to work through, construct, and then convey or perform a meaningful analysis by re-editing the film for its making that completely convinced me of the merits of videographic approaches as analytical, pedagogical, and creative research processes. The more I allowed myself to respond freely to the material as I was experiencing it through the audiovisual, spatiotemporal affordances of my editing programme with "a gestural use of editing" (Basilico 2004, 30 ), the more new knowledge about the film I seemed to produce. 


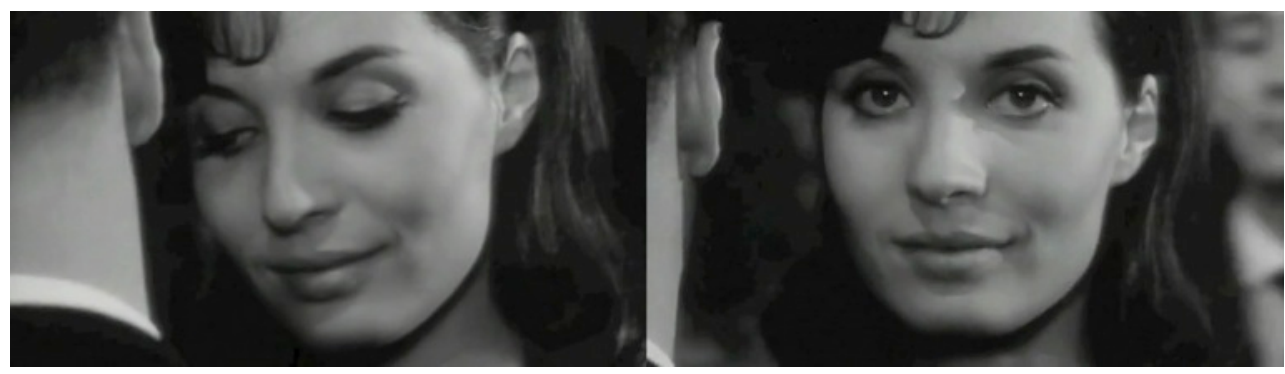

Figure 2: Screenshots from Unsentimental Education (C. Grant, 2009). | ( ) Paris Film/Panitalia. The re-edited sequence from Les Bonnes femmes features Karen Blanguernon's uncredited performance as "La fille du bal"

How better to understand the intense affective charge of the moment in the final sequence of Chabrol's film when a previously unseen character breaks the film's "fourth wall" (see figure 2, above), I found, than to experiment with reframing it, attempting to retain the feeling of that charge in the new form of a transformative work? This sequence had never really come up much in my classes; it isn't the most famous, or the most representative, example of direct address in Nouvelle Vague cinema by some distance (see, for instance, Brown 2011 for more prominent examples). But it had obsessed me in my viewings of the film over the years, and this obsession returned, redoubled, at my iMovie-editing interface. Reworking this extracted scene, reacting to it materially, first by crafting a verbal accompaniment and then by performing it vocally, precisely, over the very instant of eye contact, was exactly where I relived an especially dramatic "cinephiliac moment" (Keathley 2000) as the "shudder of an idea” (Bolt 2004a, echoing Kierkegaard; see Olson 1984, 254). This (for me, uncanny) experience of repeatedly handling the sequence in and out of its original context did indeed produce new affective knowledge about it regarding the film's explorations of temporality and temporal experience throughout its duration, and particularly about the implacable logic of its film characters' captivity in human (and cinema) time:

\footnotetext{
“On high, the glitterball doesn't just glitter; it mirrors. It witnesses and fragments what lies beneath: the 'special occasion' that punctures the endless dull time, which imprisons us all. But we are held by the spectacle, waiting for something to happen. And then it does: the troubling moment when the character - as in so many other New Wave films - returns our gaze. What does she want to happen? And what do we want to happen?" (Voiceover excerpt from Unsentimental Education, 2009)
}

Working towards the production of a video essay that, like the film itself, culminated in this moment of spatiotemporal, or spectatorial, "puncture" materialised this knowledge, and made me perform it affectively, as videographical thinking-feeling "with rhythm and timing" (Bergstrom, in Stork and Bergstrom 2012) - that is to say, 
poetically. Looking back now at this work, the creative digital context of the research allowed space for the establishment and working through of an unusually vivid relationship of aesthetic reciprocity with Les Bonnes femmes. Producing Unsentimental Education as an explanatory but also cinephiliac study helped me both to seek "the 'film behind the film' [...] the main aim of textual analysis" (Mulvey 2006,146 ), and, more unusually, to bring my version of that "hidden film" into audiovisual existence.

\section{III.}

"Part of what I love about Vine is its in-the-moment-ness, which harkens back to the ol' days of shooting one-reel films, where you only have one shot to get what you want, and if you miss it, it's gone." (Proctor 2013a)

"The blessed damozel leaned out

From the gold bar of Heaven;

Her eyes were deeper than the depth

Of waters stilled at even [...]." (Rossetti 1850, 1913)
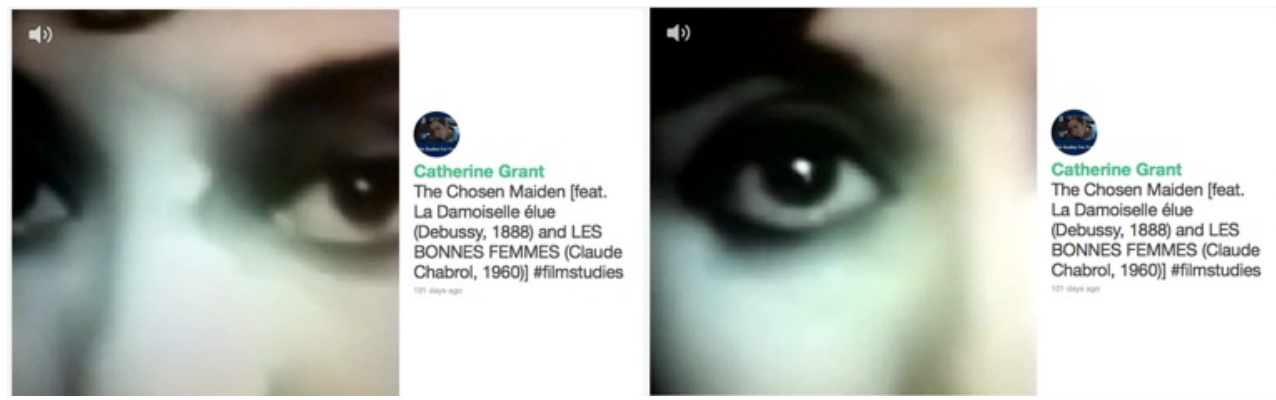

Figure 3: Screenshots from The Chosen Maiden (Catherine Grant, 2013) | (c) Paris Film/Panitalia

At some point in the first half of 2013 (around four years, and some fifty or so further video experiments under my belt after Unsentimental Education), I heard about Vine, one of a number of emergent mobile device applications for creating very short looping videos to share with fellow app users, as well as online. Flora Magdalena Olszanowski and Will Lockett describe the app's affordances, in their contribution to a collection of studies on Vine at In Media Res (2013), as follows:

"[T]he video recording begins as the user touches the screen of their mobile device, and the recording takes place only so long as they're touching the screen. Given this touch-and-hold interface, there's no [inapp] post-production editing: edits can be made by letting go of the touch before the end of the six seconds, framing a new shot, and then touching again to capture the next image in the montage." 
Vine appeared in mobile application stores in January of that year (Crook 2013), and had caught on particularly quickly with Twitter users, partly because of the app's easy integration with its parent platform. By September, once again driven by the curiosity of Mulvey's "pensive spectator," I decided to play with it, particularly to see what kinds of film studies research, if any, could be carried out within the constraints of the app's six seconds-long, square-framed video loops.

Inspired by Kenneth Goldsmith's academic and pedagogical experiments with "Uncreative Writing" - forms of material textual exploration and re-performance, through, inter alia, reflexive transcription techniques, including direct replication and "patchwriting" (Goldsmith 2011) - I settled on the technique of re-filming filmfootage using my mobile phone video camera, difficult in itself with a hand-held device, but even trickier within Vine because the square shape of its viewfinder necessarily entails choices about what to select within any (usually rectangular) cinematic aspect ratio. Very quickly I realised that the app would provide an interesting way of focusing in on, capturing and then looping cinematic gestures, such as that of Jean-Paul Belmondo running his thumb over his lips in $A$ Bout de souffle (Jean-Luc Godard 1960), the subject of my first Vine (Belmondo as Bogie in A BOUT DE SOUFFLE (Godard, 1960), 2013).

For my second experiment, perhaps dissatisfied by the fact that in the Belmondo sequence I had chosen to re-film, the actor addresses his own reflection, not the camera or spectator, I returned to my "cinephiliac moment" at the end of Les Bonnes femmes (see figure 3 , above). Or, rather, I went back to my remaking of that moment in my Unsentimental Education video, a copy of which was what I actually had to hand when I was messing around with Vine at that point. I played the video essay on my computer screen and tried to capture the moment of "contact" of the character's direct address. No conscious preconceptions about "(un-) creativity" or even about "film studies" got in the way. I just tried as best I could to capture the look of "La fille du bal" in a way that satisfied me - a very close up, rapidly moving shot of both her eyes was what I intuitively set out to achieve. It took only two takes - the six second duration of the necessarily moving, handheld shot does ensure that somewhat involuntary, purely reactive techniques are in the ascendant. The second, successful, attempt was thrilling and, for me, insightful. As with my earlier voiceover discovery in Unsentimental Education, my inexpert yet lucky handling of the re-filming tools at once reperformed and recorded the precariousness of achieving the moment of ocular contact, thus making it much more palpable.

The shudder of an idea produced by this, in every sense, ephemeral research process was a new material understanding of the 
personal charge of this particular instance of direct address. In this moment, the film not only opened up a surprising and compelling space for character-spectator intimacy (a quality frequently connected with examples of "breaking the cinematic fourth wall," as Tom Brown argues in his magisterial study of this phenomenon: Brown 2012), but also for a particularly captivating and uncanny coup de foudre-like encounter: the eyes of this anonymous female character will always meet and magically mirror mine (and yours, if you look, too) across our separate, crowded worlds. Just as, in the film's diegesis, she waits to be singled out and chosen to dance by a darkhaired stranger in a troubling repetition of the film's earlier plot (as we may notice while we try to work out why we haven't seen these characters before in the film), we spectators are made to wait for meaning by the film, and are rewarded by being singled out and chosen (individually and en masse) to return her gaze. In its original duration, the scene powerfully stages, for me at least, an instance of, as well as an occasion for, what psychoanalyst Christopher Bollas has called the "aesthetic moment," when "the subject is captured in an intense illusion of being selected by the environment for some deeply reverential experience" (Bollas 1987, 39), a concept I happened to have been exploring in relation to other cinephile experiences in recent research (Grant 2012b; Grant 2014).

My material thinking-through of this sequence did not end there, though. Unusually, for a Vine, I went on to re-edit my first recording on my mobile phone to add music that wasn't taken from the original film sequence. Then I re-filmed the result, and finally shared the video as a loop. For the new soundtrack, I used the first six seconds of a piano recording of La Damoiselle élue ("The Blessed Damozel"), Debussy's 1888 work originally for two soloists, female choir, and orchestra. I thought of this favourite piece of music for this purpose primarily because of its apt title (which I alluded to when I named the Vine The Chosen Maiden [2013]) But the overall mood of La Damoiselle élue, with the contemplative spacing of its first notes also seemed to suit the re-filmed images. As I was preparing to write this reflection, I discovered that Debussy had based his cantata on Pre-Raphaelite painter Dante Gabriel Rossetti's 1850 poem "The Blessed Damozel," which he also later illustrated in an oil painting by the same title in 1875-78. Curiously, and (consciously) unbeknown to me when I made the Vine, all these works turn out to stage an uncanny ocular encounter - and a direct address - across a normally unbreachable divide: a prematurely deceased Damozel looks down from heaven to observe her still earth-bound, still alive lover, and expresses her unfulfilled yearning for their reunion.

As my discussion above reveals, as does the sheer number of audiovisual studies involving moments of direct address that I have been drawn to making (see Grant 2013b for some examples; Grant 2014), I believe that cinephiliac videographic explorations are par- 
ticularly generative when it comes to the working through (or the acting out) of (my) unconscious spectatorial processes. Although I'm still not sure why I (and presumably others, judging by the relative ubiquity of these moments in the cinema at least) may be so deeply and at times uncannily attached to "breaking the fourth wall" moments, I will undoubtedly go on to produce much more exploratory "talk" about this. But, in the meantime, it is clearer to me that The Chosen Maiden loop, the final sequence of Unsentimental Education before it and many of my other videos have bought into being perhaps insubstantial yet always material traces of what Paul Sutton has called the dynamic, "reconstructive and creative" aspects of "Nachträglichkeit spectatorship," following Freud's concept of afterwardsness:

This process of spectatorship recreates the films it "remembers" and articulates a certain kind of love at first sight (always already at second sight) of the cinema, the expression of a kind of après-coup of the coup de foudre. (Sutton 2004, 386)

My Vine experiment, my first video essay, and many others since, do seem to me effectively to record and re-perform the "flashes of another [more subjective] history" (Keathley 2000). Viewed together, they are forging an ongoing cinephiliac archive for my creative explorations of spectatorial experiences in the (post-)digital age. For now, I know that in placing my facticity as a researcher and cinephile in relation to the at once "possessive" and "pensive" handling affordances of digital editing technology, I, like others, have been able to unconceal and materially think through knowledge ("possession" by a cinematic look?) that I would have once disavowed, or denied, as I searched for much more "acceptable" scholarly objects.

\section{REFERENCES}

Basilico, Stefano. 2004. "The Editor." In Cut: Film as Found Object in Contemporary Video, edited by Stefano Basilico, 29-45. Milwaukee: Milwaukee Art Museum.

Bollas, Christopher. 1987. The Shadow of the Object: Psychoanalysis of the Unthought Known. London: Free Association Books. 
Bolt, Barbara. 2004a. "The Exegesis and the Shock of the New." Text 3. http://www.textjournal.com.au/speciss/issue3/bolt.htm. Accessed 30 December 2013.

- - . 2004b. "Heidegger, Handlability and Praxical Knowledge." Australian Council of University Art and Design Schools Conference.

http://acuads.com.au/conference/2004conference/article/heidegger-handlability-and-praxicalknowledge/. Accessed 30 December 2013.

-_- 2007. "The Magic is in Handling." In Practice as Research: Approaches to Creative Arts Enquiry, edited by Estelle Barrett and Barbara Bolt, 27-34. London: I.B. Tauris.

Brown, Tom. 2012. Breaking the Fourth Wall: Direct Address in the Cinema. Edinburgh: Edinburgh University Press.

Crook, Jordan. 2013. “Twitter's 6-Second Video Sharing App, Vine, Goes Live In The App Store.” Tech Crunch, January 24. http://techcrunch.com/2013/01/24/twitters-video-sharingapp-vine-goes-live-in-the-app-store/. Accessed 30 December 2013.

Goldsmith, Kenneth. 2011. Uncreative Writing: Managing Language in the Digital Age. New York: Columbia University Press.

Grant, Catherine. 2008a. "Auteur machines? Auteurism and the DVD." In Film and Television After DVD, edited by James Bennett and Tom Brown, 101-115. London: Routledge.

-_- 2008b. "Online Film Audio-Commentaries and Video Essays Of Note" Film Studies For Free, 28 November.

http://filmstudiesforfree.blogspot.co.uk/2008/11/online-

film-audio-commentaries-and.html

_-_. 2012a. "Bonus Tracks: The Making of Touching the Film Object and Skipping ROPE (Through Hitchcock's Joins)." Frames 1.1. http://framescinemajournal.com/article/bonus-tracks/. Accessed 30 December 2013.

_-_. 2012b. "Uncanny Fusion? Remixing Childhood Cinephilia." Paper presented at "The Use of An Illusion: Childhood Cinephilia, Object Relations and Videographic Film Studies," University of London Screen Studies Group Seminar (with Christian Keathley), London, 3 December.

———. 2013a. "Déjà-Viewing? Videographic Experiments in Intertextual Film Studies." Mediascape Winter.

http://www.tft.ucla.edu/mediascape/Winter2013_DejaViewin g.html. Accessed 30 December 2013.

- - - 2013b. "Breaking the Fourth Wall: Direct Address and Metalepsis in the Cinema and other Media” Film Studies For Free, 15 April. 
http://filmstudiesforfree.blogspot.com/2013/04/breakingfourth-wall-direct-address-and.html.

- - - 2013c. "How Long is a Piece of String? On the Practice, Scope and Value of Videographic Film Studies and Criticism". Presentation at the Audiovisual Essay Conference, Frankfurt Filmmuseum/Goethe University, 23-24 November, 2013. Recording online:

http://filmstudiesforfree.podbean.com/2013/12/18/howlong-is-a-piece-of-string-on-the-practice-scope-and-value-ofvideographic-film-studies-and-criticism-a-talk-by-catherinegrant/.

- - . 2014. "Uncanny Fusion: Remix and the "Transformational Object." Paper presented at "Moving Objects: Film, Relation, Change" Symposium, Birkbeck University of London, 17 January.

Keathley, Christian. 2000. “The Cinephiliac Moment.” Framework 42. http://www.frameworkonline.com/Issue42/42ck.html.

Accessed 30 December 2013.

- - - 2011. "La Caméra-Stylo: Notes on Video Criticism and Cinephilia." In The Language and Style of Film Criticism, edited by Alex Clayton and Andrew Klevan, 176-191. London: Routledge.

Loh, Maria H. 2007. "Still Life: An Interview with Laura Mulvey." The Art Book 14.1. Accessed 30 December 2013.

http://www.ucl.ac.uk/art-

history/about_us/academic_staff/dr_maria_loh/mulvey_still _life

Michelson, Annette. 1990. "The Kinetic Icon in the work of Mourning: Prolegomena for the Analysis of a Textual System." October 52, Spring: 16-39.

Mittell, Jason. 2010. "How to Rip DVD Clips." The Chronicle of Higher Education [Professor Hacker Column], 12 August. http://chronicle.com/blogs/profhacker/how-to-rip-dvdclips/26090. Accessed 30 December 2013.

Mulvey, Laura. 2006. Death $24 x$ a Second: Stillness and the Moving Image. London: Reaktion Books.

Olson, Carol. 1984. "Re-Searching Unique Experience for Our Experience: Kierkegaard's Question and Method." Phenomenology and Pedagogy 3.2.

http://ejournals.library.ualberta.ca/index.php/pandp/article/ viewFile/14950/11771. Accessed 30 December 2013.

Olszanowski, Flora Magdalena, with Will Lockett. 2013. "Rhythm Aesthetics: Vine \& contemporary mobile moving image pro- 
duction practices." In In Media Res: Vine and the Short-Form Video [November 4 - November 8], 5 November 2013.

http://mediacommons.futureofthebook.org/imr/2013/11/05 /rhythm-aesthetics-vine-contemporary-mobile-movingimage-production-practices. Accessed 30 December 2013.

Proctor, Jennifer. 2013a. "That's a really interesting [comment]." In Media Res: Vine and the Short-Form Video [November 4 - November 8], 4 November 2013.

http://mediacommons.futureofthebook.org/imr/2013/11/04 /listening-vine\#comment-4694. Accessed 30 December 2013.

Rossetti, Dante Gabriel. 1913. "The Blessed Damozel [1850].” In The Poetical Works. 2 vols., edited by William Michael Rossetti. Boston: Little, Brown. I, 1-7.

Scherer, Christina. 2001. Ivens, Marker, Godard, Jarman - Erinnerung im Essayfilm. Munich: Wilhelm Fink Verlag.

Stork, Matthias and Janet Bergstrom. 2012. "Film Studies with High Production Values: An Interview with Janet Bergstrom on Making and Teaching Audiovisual Essays." Frames 1.1. http://framescinemajournal.com/article/film-studies-withhigh-production-values/. Accessed 30 December, 2013.

Sutton, Paul. 2004. "Afterwardsness in film." Journal for Cultural Research 8.3: 385-405.

\section{FILMOGRAPHY}

A Bout de souffle [feature film] Dir. Jean-Luc Godard. Société Nouvelle de Cinématographie/Productions Georges de Beauregard/Impéria, France, 1960. 87mins.

Belmondo as Bogie in A BOUT DE SOUFFLE (Godard, 1960) [usergenerated content, online] Creat. Catherine Grant. 16/09/2013, 6secs [looping]. https://vine.co/v/hnUUtKIiV96 (accessed 30.12.2013).

Les Bonnes femmes [feature film] Dir. Claude Chabrol. Paris Film/Panitalia, France/Italy, 1960. 100mins.

The Chosen Maiden [user-generated content, online] Creat. Catherine Grant. 22/09/2013, 6secs [looping].

https://vine.co/v/hrZHqnQ9Wam (accessed 30.12.2013). 
Cinematic Direct Address Part One: Mapping the Field [user-generated content, online] Creat. Catherine Grant with Tom Brown. 25/3/2013, 17mins 28secs. https://vimeo.com/62652453 (accessed 30/12/2013).

Cinematic Direct Address Part Two: You Looking at Me? [usergenerated content, online] Creat. Catherine Grant with Tom Brown. 9/4/2013, 18mins 40secs.

https://vimeo.com/63654511 (accessed 30/12/2013).

Unsentimental Education [user-generated content, online] Creat. Catherine Grant. 30/06/2009, 13mins 32secs. https://vimeo.com/5392396 (accessed 30/12/2013).

You Looking at Me? [user-generated content, online] Creat. Catherine Grant. 24/2/2013, 2mins 42secs.

https://vimeo.com/60388474 (accessed 30/12/2013). 